The UN Sustainable Development Goal (SDG) on decent work and economic growth dovetails with recently published work to develop a comprehensive approach to assess the burden of work-related injury, disease, and distress. Overall, decent work is work that has a low burden of morbidity, mortality, disability, cost, and psychosocial impacts. Generally, this burden has been incompletely portrayed and underestimated. To address this underestimation a comprehensive framework for burden has been developed. The framework includes four elements:

1. utilising multiple domains, including the individual worker, the worker's family, the community in which the workplace is located, the employer, and society as a whole;

2. taking a broader view of the work-relatedness of disease;

3. assessing the impact of the entire working-life continuum; and

4. applying the comprehensive concept of 'well-being' as an indicator in addressing contemporary change in the nature of work, the workforce, and the work place.

Measuring the burden in these elements and their composite may serve as benchmarks to gauge progress on meeting SDG targets for decent work. For this to be practical there needs to research on developing and measuring these individual elements of burden and determining the means to integrate them. This may involve looking beyond the traditional sources of surveillance data.

Various concepts in the proposed burden elements are resonant with the SDG goals and targets. For example, underemployment and unemployment which appear to have similar health effects are resonant with the target of full and productive employment. Similarly, full and productive employment should be considered across the whole working-life continuum. Taking a comprehensive view of burden and applying it to the SDG targets is worth considering and this presentation will establish that proposition.

Disclaimer The opinions in this presentation are those of the author and not necessarily of the National Institute for Occupational Safety and Health.

\section{4d HOW DOES A CATERPILLAR GROW ITS WINGS? HOW OCCUPATIONAL HYGIENE CAN CONTRIBUTE TO THE SUSTAINABLE DEVELOPMENT GOALS}

HJ Hiddinga-Schipper. International Occupational Hygiene Association (IOHA), Sint Pancras, the Netherlands

\subsection{6/oemed-2018-ICOHabstracts. 1701}

How can we, people working within the field of occupational hygiene and health, support the sustainable development goals? The latest figures show that 2.78 million workers continue to die each year from work-related injuries and illnesses. Especially when we realise ourselves that 2.4 million of these deaths can be attributed to work-related diseases alone. With this information in our minds we have to support the SDG in order to achieve a, healthy sustained, inclusive economic growth for everybody in the future.

The first important step is to consider what is the desired effect we want and which strings do we have to pull for this desired effect. In this presentation we will look for information which can help us to decide which choices we have and what the mechanisms might be that sort the best effect.

The second question to be answered is how should we approach the problems we have to solve? It is clear that to achieve the 17 intertwined Sustainable Development Goals before 2030 we will need 'all hands on deck' and we have to get in to motion. So how can the diversity of our backgrounds drive the innovation for new ideas, perspectives and solutions.

This presentation will focus on the idea that we need to change to achieve these goals, and that this can only happen if we can we overcome the challenges and see and share the opportunities we have in this connected world.

\section{4e PERSPECTIVES FROM THE ICOH SCIENTIFIC COMMITTEE ON OH \& DEVELOPMENT}

D Gagliardi. Italian Workers' Compensation Authority (INAIL), Rome, Italy

\subsection{6/oemed-2018-ICOHabstracts. 1702}

Particularly in middle- and low-income countries, workers lack basic/adequate occupational health and safety coverage, while often working in conditions with the highest risks of occupational and work-related diseases and accidents. Less than $80 \%$ of the workers of the world have access to occupational health services; in general, workers with the highest needs have the lowest coverage in term of health services and protection.

On the other hand, health and work ability of the working population is a key asset to sustainability, as the input of the global workforce provides a total global gross domestic product of USD 75 trillion per year, which sustains many other societal activities, including health and social services, training and education, research and cultural services. In addition, human labour is also behind the most intangible assets of society such as sustainability of the social fabric, level of education, general knowledge and social cohesion.

Occupational health in general can contribute to the achievement of some specific SDGs, with special reference to SDGs 1, 3 and 8, whose targets can be achieved also by developing specific occupational health and safety action aimed at improving working conditions and social protection.

According to its policy, the Scientific Committe on Occupational Health and Development (SOCHDev) focuses its interest on the relation between occupational health and development, with the aim of finding solutions and providing tools and godd practicese to improve occupational health and safety even when resources are scarce.

The most important function of the Committee is facilitating networking between those interested and active in issues of occupational health and development both in developing and industrialised countries; to achieve its objectives the Committee is engaged in providing action-oriented rather than research-oriented communication to its members and the $\mathrm{OSH}$ community, examples of SCOHDev activities and products will be presented during the presentation. 